CHAPTER 8

\title{
Teleology and natures in Descartes' Sixth Meditation
}

Karen Detlefsen

\section{INTRODUCTION}

Here are three features of Descartes' philosophy relevant to the issue of teleology. ${ }^{1}$

Feature I: Descartes famously rejects the use of teleological explanations in natural philosophy (7: 55, 2: 38-39; 7: 375, 2: 258; 8A: 15-16, I: 202-3; 8A: 8I, I: 248-49; 5: 158, 3: 34I).

Feature 2: In the Sixth Meditation, Descartes seems to give a teleological account of the sensations of the human mind-body composite, saying that it is perfectly legitimate to account for certain characteristics of the composite in teleological terms while, at the same time, rejecting the legitimacy of teleological explanations in the case of purely material systems including living bodies - a clock or a non-ensouled human body, for example (7: 82-85, 2: 575-9).

Feature 3: Descartes routinely makes use of teleological-sounding explanations in his biological ${ }^{2}$ works where he describes and explains the functional behaviors of non-human living bodies as well as of the living human body considered (counterfactually) in isolation from its soul (e.g. 6: 46ff., I: I34ff.; II: 244 ; II: 43I).

Take any pair of these features and there is a tension - three tensions in all. My goal with this chapter is not to sort out all aspects of Descartes'

I am grateful for stimulating discussion with and questions from audiences at the following conferences and colloquia: The Life Sciences in Early Modern Philosophy: A Workshop (Princeton University), Johns Hopkins--Penn Early Modern Working Group (Johns Hopkins University), SPAWN 2009: Nature and Purpose in Early Modern Philosophy (Syracuse University), A Day with Descartes (University of Toronto), Annual Lecture Series, Center for Philosophy of Science (University of Pittsburg), Fordham University, and University of Massachusetts, Amherst. This material is based upon work supported by the National Science Foundation under Grant no. 0432156 .

"I use the term "teleology" for ease of expression while being mindful that this term did not actually appear until Christian Wolff coined it in 1728 (Wolff [1728] 1983). I use it, as did Wolff, to designate that part of natural philosophy that deals with the ends of things or the purposes which they serve.

2 I use the term "biological" to refer to Descartes" works in which he investigates living beings. For more on this, see section VI, below. 
position on teleological explanations, human composites, and other living bodies; that project requires a more sustained discussion than I can give it here. Rather, my goal is to look more closely at the Sixth Meditation passage - especially in light of some helpful conceptual background as a first step in gaining a global picture of Descartes' thought on teleology. Some of the more general, schematic conclusions near the end of the chapter indicate the more general picture I aim to develop in a longer, more sustained treatment of this subject in Descartes.

\section{DESCARTES' SIXTH MEDITATION PASSAGE}

Here is the Sixth Meditation passage, which seems to stand in tension both with Descartes' anti-teleology claims and with his teleologicalsounding explanations in the life sciences:

I must more accurately define exactly what I mean when I say that I am taught something by nature ... My sole concern here is with what God has bestowed on me as a combination of mind and body. My nature, then, in this limited sense, does indeed teach me to avoid what induces a feeling of pain and to seek out what induces feelings of pleasure, and so on.

[W] hen I consider the purpose of the clock, I may say that it is departing from its nature when it does not tell the right time; and similarly when I consider the mechanisms of the human body, I may think that, in relation to the movements which normally occur in it, it too is deviating from its nature if the throat is dry at a time when drinking is not beneficial to its continued health. But I am well aware that "nature" as I have just used it has a very different significance from "nature" in the other sense [as applied to the human composite]. As I have just used it, "nature" is simply a label which depends on my thought; it is quite extraneous to the things to which it is applied ... But by "nature" in the other sense I understand something which is really to be found in the things themselves; in this sense, therefore, the term contains something of the truth.

When we say, then, with respect to the body suffering from dropsy, that it has a disordered nature because it has a dry throat and yet does not need drink, the term "nature" here is used merely as an extraneous label. However, with respect to the composite, that is, the mind united with the body, what is involved is not a mere label, but a true error of nature, namely that the body is thirsty at a time when drink is going to cause the body harm. (7: 82-85, 2: 57-99; emphases added; translation altered)

At this point, I highlight the following two initially crucial features of this passage. First, Descartes makes a clear distinction between a clock and a living human body on the one hand (and one can add any non-ensouled living body to this category), and the human being (or mind-body composite) on the other hand. Second, the latter but not the former is treated in self-consciously teleological terms. That is, Descartes here indicates 
that certain physiological behaviors that typically fall under the purview of natural philosophy are beneficial or barmful to the mind-body composite, and that the sensations (e.g. pleasure and pain) are functionally useful in identifying those behaviors. We sense the world around us in the way that we do so as to be better able to preserve our bodies.

Unsurprisingly, this passage has attracted much attention, not least of: all because of Descartes' pronouncements elsewhere against the reliance on teleological explanations in natural philosophy. Jean La Porte (1928) and Alison Simmons (200I) have both provided prima facie compelling readings of this passage, and I present critical features of these readings here. Simmons, for example, argues as follows. Descartes does take the mind-body composite to be a teleological system, uniquely so in the natural world (clocks, human bodies, and dogs, on the other hand, are not teleological systems). Certain features of the teleological system that is the human composite - sensation, especially, but other physiological processes such as digestion as well - serve the end of the mind-body composite. This end is survival, specifically the survival of the body in a state suitable to allow the mind to continue to be united with it (Simmons [200I], pp. 53 and 55-56).

Simmons, La Porte, and others are, of course, mindful of the possible problems that arise for this teleological reading of the Sixth Meditation passage, most notably the tension between this reading and Descartes' anti-teleology pronouncements (Feature I, above). Roughly, Simmons resolves the tension as follows (Simmons 200I, pp. 64ff.). She first notes the medieval distinction between divine, rational, and natural teleology. Divine teleology is the attribution of ends to God, especially in his creation of the universe and its parts. Rational teleology is the attribution of ends to rational creatures in their conscious deliberation. Natural teleology is the attribution of ends to non-rational bodies and their parts. Simmons then claims that Descartes' anti-teleology passages banish divine and rational teleology from physics, but that these passages need not be read as banning natural teleology from physics. That is, as long as the attribution of ends to natural systems does not intrude in the search for the efficient causes of the behaviors under investigation, natural teleology is perfectly legitimate in Descartes' philosophy. Finally, Simmons argues both that the form of teleology that we find in the case of mind-body composites in Descartes is natural teleology, and that this natural teleology does not interfere in the search for the efficient cause of the behaviors in question.

Simmons does identify a potential problem with this approàch. "In a theistic framework, it might seem a short step from proscribing divine teleology to proscribing natural teleology. If God creates the natural 
world, the thought goes, then surely any ends in nature are really God's ends" (Simmons 200I, p. 66). La Porte also identifies this problem and deals with it by offering the important distinction between the ends God has when he creates, and the ends he conveys to the things he creates ( $\mathrm{La}$ Porte 1928, pp. 37I-75). ${ }^{3}$ Simmons picks up this distinction:

There is an ambiguity lurking in this line of thought [which holds that proscribing divine teleology leads to proscribing natural teleology], for it fails to distinguish between (a) the ends that move God to create and (b) the ends of the things he creates. Perhaps God creates eyes because he wants his creatures to get around by seeing and he determines that the eyes are a means to sight ... This is a matter of divine teleology about which Descartes claims the natural philosopher has no business making guesses. It is a further question whether the eyes that God creates serve the creature's end of survival. To be sure, it is God who decides that this sort of creature have the sort of means-and-ends structure that it does. God is thus the source of creaturely means and ends. But the creature's ends are not God's ends (except in the limited sense that he decides to create them); they are ends with which (not for which) God creates them. (Simmons 200I, pp. 66-67)

I think La Porte and Simmons are on to something crucial in highlighting this distinction, but it is not fully nor explicitly stated. As it stands, one might (uncharitably) reply to Simmons' defense just quoted as follows. If we explain the harm done by dropsy, for example, to the human composite in terms of the ends of the composite that God bestowed upon that composite, we are ultimately making reference to God's purposes with respect to the composite, and this is illegitimate. That is, whether we refer to God's broader, theological ends, which urge him to create (such as his purposes with respect to the human's place in the universe), or we refer to God's narrower, physical ends, which are reflected in the living beings he has produced (such as his purpose to structure organisms in such a way that will permit them to function toward self-maintenance), we are ultimately making unwarranted reference to God's purposes. ${ }^{4}$ Indeed, one can identify two possible misgivings one might have about the $\mathrm{La}$ Porte/Simmons approach at this juncture. First, as we shall see below, Descartes is opposed to any claims in natural philosophy which depend upon our supposing to know God's purposes vis-à-vis the natural world, and this presumably holds regardless of whether we claim to know God's

${ }^{3} \mathrm{La}$ Porte notes that this.crucial distinction is used by St. Thomas, and repeated by Gibieuf, whose work would have been the source of Descartes' own knowledge of the distinction.

4 I take this to be Des Chene's conclusion with respect to teleology in Descartes as well. Des Chene (1996), pp. 391ff: 
purposes directly and immediâtely, or ,indirectly and mediated by what we,find in the mind-body composite. Second, and related, any explanation"which relies upon making reference to God's ends (directly or indirectly), is an explanation which relies upon something "extraneous" to the mind-body composite (God) iwhich runs counter to Descartes' explicit claims in the Sixth Meditation that the composite is different from everything else because of its intrinsic teleological nature - a nature "which is really to be found in the things themselves" - a nature which can and must be explicated wholly in terms of itself without any reference at all to anything outside of itself, including God.

\section{SOME HELPFUL CONCEPTUAL BACKGROUND ON TELEOLOGY}

Teleological, thinking is sometimes thought to belong to one of two main strains - what one might call "natural" teleology and "unnatural" teleology, with the former capturing a broadly Aristotelian approach and the latter capturing a broadly Platonic approach.s Aristotelian teleology is an immanent or intrinsic teleology according to which the goal or end is intrinsic to the being itself, which thus has an internal, end-directed principle of change. The being need not be conscious or aware of this intrinsic end. Platonic teleology is extrinsic or external teleology according to which the end or goal of a being is found in the mind of an external agent. The external agent is conscious and aware of this goal, and the end or goal is not the being's end or goal, but the agent's. The model of a craftsman who, with purposes in mind, builds an artifact that can fulfill those purposes is a typical example of Platonic teleology. ${ }^{6}$

In order to develop what I take to be the promising kernel in the $\mathrm{La}$ Porte/Simmons approach, and to therefore provide a more charitable reading of Simmons' quoted defense than the one offered at the close of the previous section, in this section I sketch some crucial elements of these two versions of teleology. I turn to Plato and Aristotle themselves not because these would have been Descartes' historical sources, but because the thinking of these two figures on teleology exhibits very clearly some conceptual principles helpful for thinking about Descartes' approach to the topic. Moreover, there are very few historically significant

s The term "unnatural teleology" used for the Platonic variety is James Lennox's. See Lennox (1985).

- For a more detailed treatment of these strains, see Lennox (1992), pp. 325-26. 
versions of purely Aristotelian teleology thăt post-date Aristotle. Most versions of teleology that include Aristotelian elements also include Platonic elements. And so it is helpful to turn to Aristotle himself to present the Aristotelian strand of teleology. One final remark: while a sustained treatment of our ancient figures is certainly warranted, here I merely draw some crucial, pertinent conclusions and working principles from their philosophies in order to return to a discussion of Descartes' Sixth Meditation passage.

\section{General conclusions}

(I) Plato and Aristotle both propose a need for teleology to account for certain features of the natural world - including living beings because they believe that chance (taken in opposition to purpose) cannot explain these features. For Plato, the feature that cannot be explained by chance is beauty taken as that which is orderly and well-proportioned (Tim. 30a3-6 and 69b2-4), characteristics of the universe, which require intelligence and reason (Tim. 46e3-6). Aristotle's rejection of chance and his consequent embrace of: teleology emerge from his rejection of the chance accounts of the generation of living beings given by his materialist predecessors such as Empedocles - accounts which Aristotle thinks are impossible because they cannot account for the facts of living beings such as their functional unity and their being alive (e.g. Phys. II, 8; 198b23-32).

(2) Aristotle makes a further teleological distinction between intrinsic and incidental ends (e.g. Post. I, 4; 73bio-I5, and EE vII, I3; 1246a26-31). An intrinsic end is an end which accords with a being's own nature, while an incidental end is one that does not accord with a being's own nature. So, for example, a dog has both an intrinsic end, e.g. survival, which accords with its own nature, and an incidental end, e.g. fighting to the death with another dog to entertain humans, which does not accord with its own nature. According to Aristotle, living beings have both intrinsic and incidental ends, while artifacts have only incidental ends. This is related to the fact that artifacts qua artifacts have no intrinsic natures, with a nature

\footnotetext{
${ }_{7}$ Garrett (1999) thinks Spinoza has an essentially Aristotelian form of teleology. See note 9, below, for an example of blended forms of teleology.
} 
in this instance being conceived of as an inner principle of change toward an end definitive of the kind of being it is (e.g. Phys. II, I; I92b33).

(3) According to Aristotle, only beings with intrinsic ends can be the subject of scientific study and scientific explanations (e.g. $E E$ I, 5; I2I6bio-i8).

(4) If we think of living beings as constructed out of material parts by. a craftsman - that is, if we think of them in purely Platonic terms - then an Aristotelian can conclude that living beings so conceived (a) have no natures qua living beings; (b) have only incidental ends; and (c) are therefore not the subject of scientific study and explanations.

\section{Three useful conceptual principles to extract from the above conclusions}

First, we ought not to conflate the distinction between a thing's nature on the one hand, and whether or not a teleological account can be given for that thing on the other hand. While related (as will come clear in the points which follow), these are two distinct issues.

Second, if a thing does not have an intrinsic nature to serve a specific end, a teleological account can still be given for it by making reference to something extrinsic to the thing, namely, to the mind and the goal within that mind, of the thing's builder or its user. ${ }^{8}$ Such an account will not necessarily (though it could) tell us anything about the thing considered in itself. This point applies most obviously in the case of Platonic teleology.

Third, if a thing has an intrinsic end-referred nature, regardless of how it came to have that nature, then two different sorts of teleological accounts can be given for it:

(A) One sort of teleological account makes reference solely to the thing's nature (and to nothing external to it), and this sort of account necessarily tells us something about the thing considered in itself.

(B) The other sort of teleological account makes reference to the ends found in a mind extrinsic to the thing itself, and this sort of account does not necessarily tell us something about the thing considered in itself.

${ }^{8}$ See also Carriero (2005), p. 125, including n. 23. 
This point applies most obviously in the case of Aristotelian teleology, or a blended form of teleology, which includes Aristotelian elements.

\section{REVISITING DESCARTES' SIXTH MEDITATION \\ PASSAGE, IN LIGHT OF THIS BACKGROUND}

In somewhat older literature on the seventeenth century, it is often suggested that the mechanical philosophy that dominated the century led to teleology being expunged from natural philosophy (e.g. Koyré [I950] 1965, p. 8; Taylor 1967; this is an attitude which even survives until more recent years - e.g. Clark 1995; Mackie 1995, p. 28I). Recently, this assumption has been quite effectively challenged through studies of individual seventeenth-century mechanists who nonetheless allow room for teleological explanations in their natural philosophies (e.g. Garrett 1999; Simmons 200I; Carlin 2006; McDonough 2009), ${ }^{10}$ and through more general accounts which (while perhaps not stating it in exactly these terms) demonstrate that mechanism in the seventeenth century and Platonic teleology are perfectly compatible even if mechanism and Aristotelian teleology (or forms of teleology which include an Aristotelian element) are not compatible (e.g. Osler 1996). For a mechanist, the immanent drive toward an end relies upon a form of efficient cause incompatible with mechanism, for this sort of efficient cause is not an unbounded, uniform inertial motion (as per the mechanist's efficient cause), but is a bounded motion aiming toward a specific end. ". By contrast, Platonic teleology permits explanations of the behaviors of God-built machines wholly in terms of matter in inertial motion.

So, as a mechanist, if Descartes endorses any form of teleology, it has to be purely Platonic, or at least it cannot include any Aristotelian elements. Yet Descartes also clearly dismisses Platonic teleological explanations in natural philosophy, at least in cases where the external, conscious agent is God. This is clear in all of the anti-teleology passages found in Descartes' work where he alludes to purposes external to natural beings, found in the

9 Aquinas offers such a blended account for he believes that 'God (the external agent as on the Platonic version of teleology) could have conveyed a metaphysically robust, intrinsic teleological nature (Aristotelian teleology) onto natural beings such that, these beings are able to share in God's purposes while not, themselves, being intentional beings (e.g. Aquinas [1265-72] 1952-54, 3:36). On Aquinas' account of final tause, especially as it illuminates early modern concerns, see Carriero (2005).

10 There are also dissenting views that argue against the inclusion of teleology, especially in the case of Spinoza (e.g. Carriero [2005] and Bennett [1984], pp. 213-30).

"See Carriero (2005), p. I2I. 
mind of a conscious agent (God), but 'cognitively inaccessible to us. Here is a classic example from the Fourth Meditation:

[I] $t$ is no cause for surprise if I do not understand the reasons for some of God's actions; and there is no call to doubt his existence if I happen to find out that there are other instances where I do not grasp why or how' certain things were made by him. For since I now know that my own nature is very weak and limited, whereas the nature of God is immense, incomprehensible, and infinite, I also know without more ado that he is capable of countless things whose causes are beyond my knowledge. And for this reason alone I consider the customary search for final causes to be totally useless in physics; there is considerable rashness in thinking myself capable of investigating the impenetrable purposes of God. (7: 55, 2: 38-39; emphasis added; cf. 7: 374-75, 2: 258; 8A: 15-16, I: 202; 8A: 81, r: 248-49; and $5: 158,3: 34 \mathrm{I})$.

If Aristotelian teleological explanations are elimipated from Descartes' natural philosophy because they are incompatible with mechanism and because Descartes is a mechanist, and if Platonic teleological explanations are eliminated from Descartes' natural philosophy because we cannot know God's purposes, then a number of possibilities arise. One possibility is that Descartes really does reject wholesale both Platonic and Aristotelian forms of teleology, and if these are the only two, teleological options, then there appears to be no room at all for teleological explanations in Descartes' natural philosophy. This is, of course, suggested by the first feature of Descartes' philosophy with respect to teleology which I mentioned at the outset of this chapter and which is in tension both with his use of teleological explanations in discussing the human composite, for example, in Meditation Six (Feature 2), and with his teleological-sounding explanations of non-ensouled living beings (Feature 3 ). A second possibility is that Descartes in fact does not fully reject Platonic teleology, and I think this option represents part of the truth. A third possibility is that Descartes is committed to the use of teleology, he does reject Aristotelian teleology while also accepting some form of Platonic teleology, but there is another form of teleology which he might implicitly endorse, even.if he does not fully articulate this form of teleology himself. I believe that this option, too, represents part of the truth. I deal with these two possibilities in sections $\mathrm{V}$ and VI respectively.

In this section, I will examine more closely the Sixth Meditation passage against the conceptual framework erected in the previous section. The first crucial point is that the Sixth Meditation passage is not first and foremost about teleological explanations; it is first and foremost about the natures of things, specifically, the nature of the human composite as opposed to 
the nature of purely material systems (e.g. clocks and human bodies considered without a soul). Descartes' discussion of the natures of things has implications for teleological explanations, to be sure. But as my first principle in section III, above, indicates, the natures of things and teleological explanations of things are two distinct issues. And Descartes thinks so, too, as Burman reports Descartes saying: "the knowledge of a thing's purpose never leads us to knowledge of the thing itself; its nature remains just as obscure to us" ( $5: 158,3: 34 \mathrm{I})$. Indeed, as I mentioned above, the crucial distinction between the natures of things and teleological explanations of things is implicit, even if not fully articulated, in the La Porte/Simmons approach. Recall the central distinction Simmons highlights: "(a) the ends that move God to create and (b) the ends of the things he creates." In referring to the ends of the things God creates, Simmons is alluding to the intrinsic, end-referred nature of creatures. A charitable reading, then, of the La Porte/Simmons approach picks up on and develops the implications of this nascent acknowledgment that the fundamental issue in the Sixth Meditation passage is the issue of the natures of things. My goal here is to fill out this aspect of the La Porte/Simmons approach.

What the Sixth Meditation passage indicates, then, is that the human composite has an intrinsic end-referred nature (which God has bestowed upon the composite), while wholly material systems do not have intrinsic end-referred natures (or they do not have such natures when we consider their fundamental metaphysical nature, for that is the context of this and related passages in the Sixth Meditation). Wholly material systems do not have, metaphysically, intrinsic end-referred natures, because such systems are composed merely of matter which is moving in accordance with descriptive laws of nature; there is nothing prescriptive or end-referred about this. "Yet a clock [or any other purely material system such as a dog] constructed with wheels and weights observes all the laws of its nature just as closely when it is badly made and tells the wrong time as when it completely fulfills the wishes of the clockmaker" (7: 84, 2: 58). The human composite, according to the Sixth Meditation passage, is different in its nature from merely material systems, for something within the composite itself - something intrinsic to it - is end-referred, or teleological.

We can use the principles established at the close of section III, above, to now connect the two issues of natures and teleological explanations specifically with respect to Descartes' Sixth Meditation. The second principle is relevant to the case of purely material systems, and given my interest in living bodies (Feature 3 at the outset of the chapter), I discuss this principle with respect to a dog. Dogs do not have metaphysical intrinsic, 
end-referred natures according to Descartes. Dogs do have metaphysical natures, of course. They are, by nature, composed of extension that has the capacity to take on quantitative variations in their modes - variations in, for example, the size, shape, and speed of motion of their extended parts. The material parts of these bodies all obey the laws of motion (7: 84, 2: 58), and this is true of a dog whether or not its heart beats, for example. But this nature does not embody prescriptive ends; it is not teleological. Nonetheless, we can say that the dog is well functioning or not, and it makes sense to say so because this teleological account relies upon the goals vis-à-vis the dog which are found in the mind of either its maker or its user (or both) - and so such an account tells us about the dog's 'nature' as conceived in a mind extraneous to the dog itself. This is in keeping with the second principle: Descartes' position allows that we can give perfectly legitimate teleological accounts of non-ensouled material things, but that these accounts are not grounded in the metaphysical natures of the things themselves.

A crucial corollary to this principle is that, since the dog has no intrinsic nature to achieve specific ends, then there is no ground for saying one teleological account of the dog's use is better than any other. This is because the teleological account relies entirely upon making reference to purposes extrinsic to the dog, specifically, purposes in the minds of its maker or users, all of which are equally legitimate when there is no nature intrinsic to the dog constraining its proper use. To put it in Aristotelian language, all ends of the dog are incidental; none are intrinsic. This point deserves emphasis. In the case of living bodies, we may be tempted to say that the correct teleological account of them must make reference to God's mind and his purposes in creating them. But this approach is misguided, and not simply because we (perhaps) cannot know any of God's purposes. Suppose we could know that God intended a dog to behave biologically in order to survive (as we can know that a clockmaker intended his product to tell time). If there is nothing conveyed upon the dog's nature which reflects this purpose, it is just as legitimate to give a teleological account which says that the dog is for the sake of our entertainment in a fight to the death with another dog as it is to give a teleological account which says that the purpose of the dog is its own self-preservation and so it behaves in certain ways (e.g. avoiding unnecessary, violent situations) which contribute to self-preservation. Certainly, it may be an affront to God should I use the dog in a fight to its death, just as it would be an affront to a clockmaker were I to use his fine clock to prop open a door. But this would be a comment on our relations with God (or clockmaker), 
and it would not be a comment on what can be considered proper uses of the thing itself. My relationship with God (or clockmaker) does not impact the metaphysics of objects and what follows teleologically from that metaphysics.

The third principle at the close of section III, above, is relevant in the case of the human composite. In light of the third principle, two conclusions can be drawn about the relation between natures and teleological accounts of the human composite. First, we can give a teleological account of the human composite by making reference only to the composite itself, and this account will necessarily tell us something about the composite considered in itself. To put it in Aristotelian language, this would be an explanation based on intrinsic ends. In this sort of teleological account, we need not - indeed, we cannot - ground the account by making reference to the mind of a being extrinsic to the composite - the mind of God, for example, if God created the composite. So, for example, we may say that the composite has the sensory perceptions that it does in order to serve the end of self-preservation, and in order for this account to be grounded in the composite's intrinsic nature (thereby telling us something about the composite itself) it must somehow be cashed out only in terms of features intrinsic to the composite itself. This is the principal worry behind the uncharitable reading of the approach to teleological accounts of the sensations suggested by La Porte and Simmons. If the La Porte/Simmons account relies, even indirectly, upon reference to God's ends, then the teleological account of the composite thus given would be one based on something extrinsic to the composite. To give a teleological account of the composite that relies upon and elucidates the intrinsic nature of the human composite, we need to. give an account of the composite which relies solely on features within the composite itself.

Second, despite the first conclusion just drawn, we can, nonetheless, give a teleological account of the composite by making reference to ends in a mind extrinsic to the composite; it is just that this account will not necessarily tell us anything about the composite itself. To put it in Aristotelian language, this would be an account potentially based on incidental ends. For example, suppose for now that Deseartes does not preclude our knowing God's purposes. We 'could give a teleologicat account of the human composite by making reference to God's purposes when he created the composite. This second sort of teleological account might even tell us something about the nature of the composite itself - indeed, according to Descartes in the Sixth Meditation, this second sort of teleological account does tell us something about the composite because "God 
has bestowed [a nature] on me as a combination of mind and body." But this second sort of teleological account will not necessarily tell us something about the composite itself in the same way that the first sort of teleological account (the sort which relies only upon the nature of the composite) will necessarily tell 'us something about the composite itself.

This last point becomes clear when we consider a second example, that of a doctor who gives a teleological account of an ill human being whom she is trying to cure. For example, suppose the doctor has a patient who is extremely sensitive to bright light. The doctor may give the following teleological account of the patient's symptom: due to a mechanical fault in the eyes, the patient's pupils are not closing to the degree that is prescriptively normal for human eyes, they are therefore not functioning as they ought to, and so the patient's eyes will not serve as well as possible the human's end of self-preservation. Then the doctor would prescribe a cure in order to bring the patient's eyes back to as good a state as possible. This teleological account of the patient depends at least in part upon reference to the mind of the doctor and does not necessarily tell us something correct about the human being considered in himself, a point that would be underscored should he die of meningitis a few days later.

The foregoing forces us to face a question neither posed nor answered by Simmons - nor, indeed, by Descartes himself in the Sixth Meditation. What is the nature of the composite such that it uniquely has an intrinsic, end-referred nature? ${ }^{12}$ It seems to me that to give a legitimate teleological explanation of the human being (the mind-body composite) without relying upon God's unknown and extrinsic purposes vis-à-vis the composite, it is in fact necessary to explicate the nature of the composite in order to show how. it is the grounding of that legitimate teleological explanation.

\section{THE COMPOSITE'S NATURE}

In this section, I consider three candidates for the composite's nature: (a) the composite is a hylomorphic substance; (b) the composite is a union of two distinct substances, mind and body, which retain their essential natures in the composite, and there exists a sort of satisfaction relation between mind and body such that mind confers value on the body which is, in itself, without intrinsic value; and (c) the composite is a union of two distinct substances, mind and body, which retain their essential natures in the composite, and there exists a sort of satisfaction relation between

12 This point is also made by De Rosa (2007) p. 322 n. 33. 
mind and body such that mind recognizes value in the body. There are virtues and drawbacks to each of these options, though, in the end, I think the third option stands the best chance of easing all tensions identified at the outset of this chapter.

By acknowledging the fact that the human composite has an intrinsic end-referred nature, one might be enticed to endorse the thesis that Descartes has a hylomorphic account of the human being. The hylomorphic thesis holds that Descartes, in ridding his philosophy of Aristotelian ontology, nonetheless retains one substantial form - the human soul - and so maintains that the human being is a unified composite of form (soul) and matter (the human body). Paul Hoffman, who developed one of the earliest full defenses of the thesis, puts it as follows: "Descartes believes that mind inheres in body as form inheres in matter, and ... this hylomorphism does real philosophical work for him ... Descartes's account of the per se unity of his man compares favorably with medieval accounts of per se unity, and, indeed, is remarkably close to the views of Scotus and Ockham" (Hoffman 1986, p. 342; cf. Rodis-Lewis 1950, pp. 76-8I; Grene 1986, 1991; Hoffman 1991). One might use the hylomorphic account of the human being to say that it is the process of the soul's actualizing the human body that lends the composite its intrinsic teleological nature. This does, indeed, seem to be the approach of at least some advocates of the hylomorphic thesis. Roger Ariew, for example, writes: "the human body, according to Descartes, unlike the body of an animal, has a real functional indivisibility and internal finality derived from its union with a soul" (Arî́tw 1983, p. 35, emphasis added; cf. Gueroult 1953, vol. II, pp. 180-8I).

One problem with the hylomorphic option is the fact that Descartes' biological works - including those which deal with the human body considered hypothetically in isolation from the soul, such as Treatise on Man and the fifth part of Discourse on Method - make clear that the soul does not actualize the body in any way typical of medieval hylomorphic theories. The living human body alone is able, through mechanical means, to achieve a great number of biological functions, including those which contribute to its continued unity, its continued life, and its self-preservative behaviors (cf. Rozemond 1998, pp. 170ff.) the very teleological features supposedly realized by the presence of the soul. Consider also the case of sensation, which is especially interesting in this context, for animals share with ensouled human beings the first of the three "grades of sensory response" that Descartes identifies (7: 436, 2: 294). Given their behavior in reaction to their sensations which allows 
them to preserve a well-functioning disposition of essential parts and organs (which just is tantamount to biological survival), it seems this first grade is sufficient to account for the apparently end-referred behavior of self-preservation. Finally, whatever else might be said about Descartes' supposed endorsement of hylomorphism, it is certainly not the case that the human mind within the composite has purposes vis-à-vis the composite which permit it to survive biologically - purposes which it then actively carries out.

The second candidate for the composite's nature has the twin virtues of both paying due heed to Descartes' mechanizing of all living functions, including those found within the human body itself, and accounting for the intrinsic teleological nature of the human without thereby importing unwanted teleological explanations into natural philosophy. To recall, this is the first "satisfaction relation" sketched above, according to which the composite is a union of two distinct substances, mind and body, which retain their essential natures, and there exists a sort of satisfaction relation between mind and body such that mind confers value on the body which is, in itself, without intrinsic value.

According to this approach, ${ }^{13}$ we acknowledge that the mind and body both retain their own essential natures within the composite. The body is essentially just extended matter moving in accordance with descriptive natural laws; there is nothing purposive about it. The mind's essential nature is to think, and this includes having sensations of all three grades, including mental perceptions of those sensations and judgments which follow on these perceptions. The body, as a living body, accomplishes all its living functions mechanically - that is, by matter moving in accordance with the laws of motion. The end-referred nature intrinsic to the composite comes about through a sort of "satisfaction relation" between the mind and the body. The mind has sensations due to its union with the body, and these sensations can be either pleasurable or painful. The teleological nature of the composite just is the fact of the soul's finding pleasure or displeasure in its union with the body. It is crucial to note that according to this option, the soul does not recognize that there is something beneficial or harmful occurring in the body. The soul is not alerted to the body's well-functioning or malfunctioning. The body is not the sort of thing that functions well or not; it is not the sort of thing in which beneficial or harmful events occur. It cannot be such a thing because it does not have an intrinsic

${ }^{13}$ I appreciate the discussions with Paul Guyer that led me to formulate this option. 
end-referred nature, as Descartes explicitly says in the Sixth Meditation passage. Rather, we can think of the relation between the soul and body as exactly symmetrical to the relation between a user's mind and a clock. The user of the clock sees that it is keeping the time and says that it is functioning well. But the clock is not functioning well as a timekeeper. It is simply a pile of matter obeying the laws of nature. The teleological element in this relationship is in the user's mind. This is precisely what occurs in the case of the human composite according to the present. option, only now, the body and soul are considered a unit and not two separate things, and so the soul's attributing normative claims to the (non-normative) body is intrinsic to that union, or to the relation which holds between mind and body in the composite. The intrinsic teleological character of the union comes about by the soul's conferring normative value onto the body due to the sensations it happens to have as a result of its relationship with it.

The two prime virtues of this account that I see are as follows. First, the non-teleological nature of the body is fully preserved. Thus, this approach involves no scientifically relevant teleological explanation, and so there is no tension between Descartes' general prohibition against teleological explanations and the Sixth Meditation claim about the human composite. The soul's attributing normative value to the body does no scientific work with respect to the body. The body and its behaviors are still fully explained in mechanical terms. Second, the tension between Features I and 2 of Descartes' approach to teleology is fully eased by referring to the composite itself and without making any reference at all to something extrinsic to that composite - God, for example. This is a version of Platonic teleology, but it is one in which the agent conferring purposes and value on the human body is not God, but the human mind within the composite.

There are, however, at least two drawbacks of this approach. The first and this also applies to the second satisfaction relation below - is that were this Descartes' intention, he really ought to have said something in the Sixth Meditation passage about the nature of the union of mind and body since the human composite is treated as unique in that Meditation. The mind-body composite is different from any number of other com. posites one might imagine according to a. satisfaction-relation approach: a mind-clock composite, a mind-dog composite, and so on without end: Unlike any other composite, for example; we do not have to think about the relation between mind and body for it to obtain, and it obtains for as long as we live. 
As for the body which by some special right I called "mine", my belief that this body more than any other, belonged to me had some justification. For I could never be separated from it, as I could from other bodies; and I felt all my appetites and emotions in, and on account of, this body; and finally, I was aware of pain and pleasurable ticklings in parts of this body, but not in other bodies external to it. $(7: 76,2: 52)$

What accounts for that unity? In the Sixth Meditation, Descartes does not say, and yet if either satisfaction relation were to be his considered position, he ought to have explained the nature of the union so as to not open the door to unending examples of composites. ${ }^{14}$ The second drawback is that this approach solidifies the tensions between Feature 3 on the one hand, and the other two features of Descartes' thinking on teleology as noted at the start of this chapter. That is, living bodies - human or other - have no teleological natures at all, and so the teleological-sounding explanations that Descartes uses in his biological works pose an insurmountable difficulty for him. One may think this not at problem at all. That is, one may reply that the teleological-sounding explanations of Descartes' biology, are just that - teleological sounding, but not truly teleological (Simmons 200I, p. 62n. 17). In the final section of this chapter, I return to this point, suggesting that Descartes might well rely upon quasi-teleological accounts of. biological processes in all living things in order to secure a class of living beings to serve as the subject matter of his biology.

The third candidate for the composite's nature is a different version of the satisfaction relation. Recall that according to this version, the composite is a union of two distinct substances, mind and body, which retain their essential natures in the composite, and there exists a sort of satisfaction relation between mind and body such that mind recognizes value in the body, even if it sometimes fails to do so accurately. There are two obvious virtues to this approach. First, it has textual support, even if not in the Sixth Meditation. For example: "I consider it probable that the soul felt joy at the first moment of its union with the body, and immediately after it felt love, then perhaps, also hatred, and sadness; and that the same bodily conditions which then caused those passions have ever since naturally accompanied the corresponding thoughts" (4: 604, 3: 307 emphasis added; cf. II: 399, I: 362; and II: 407, I: 365). Here good bodily conditions exist prior to, and are the cause of, the soul's reaction to those bodily conditions. The second virtue is that it at least, opens the door to the resolution of the two tensions between Feature 3 on the one hand, and

${ }^{14}$ I thank Lisa Downing for drawing my attention to this difficulty. 
the other two features of Descartes' thinking. on teleology. Of course, it promises these solutions at a potentially great cost, and this is the primary drawback of this account of the nature of the human composite. This account seems to rely upon attributing an intrinsic teleological nature to the body itself, which is in explicit conflict with what Descartes clearly says in the Sixth Meditation passage. I now turn to this supposed great cost to see if Descartes must indeed bear it were this third approach to capture his intentions.

\section{DESCARTES' BROADER 'BIOLOGICAL' PROJECT: NEXT STEPS}

Recall Aristotle's distinction between intrinsic and incidental ends. Living beings have both sorts of ends, and they have intrinsic ends because they have natures (as in inner principles of change toward ends appropriate for the kinds of beings they are). They can therefore be the subject of scientific study and explanations. Artifacts, such as built machines, have only incidental ends, because they have no intrinsic natures in the form of an inner principle of change. Consequently, they cannot be the subject of scientific study and explanations. In the Sixth Meditation passage, Descartes draws a metaphysical line between human composites on the one hand and purely material bodies on the other. Purely material bodies, according to the Sixth Meditation account, do not have intrinsic end-referred natures, and so only teleological accounts based on what Aristotle would call incidental ends (purposes in an extrinsic mind) can be given for clocks, or dogs, or human bodies considered, counterfactually, in isolation from a soul. But this is a problem, and for broadly Aristotelian reasons.

First, the Sixth Meditation characterization obliterates what is distinctive about living bodies. An account of a dog that says that it serves the purpose of entertaining us in a fight to the death with another dog is equally legitimate against a consideration of the dog's nature as an account of the dog that says that its purpose is to survive through the exercise of certain biological functions. And yet, we intuitively believe that what makes a dog different from a clock is that it functions, and properly so, in ways unique to living beings. Dogs (and other living bodies) but not clocks generate offspring, undergo change in growth, can react to their environments in order to survive some environmental wear and tear, and thus preserve themselves. The implicátion of 'Descartes' Sixth Meditation certainly runs afoul of Aristotle's intuitions about living beings, but it also runs afoul of Descartes' intuitions that there is a distinction to be 
made between the living and the non-living even while they both may be machines. In June 1642, for example, in a letter to Regius he identifies living things as a category:

[Y]ou seem to make a greater differrence between living and lifeless things than there is between a clock or other automaton on the one hand, and a key or sword or other non-self-moving appliance "on the other. I do not agree. Since "self-moving" is a category with respect to all machines that move of their own accord, which excludes others that.are not self-moving, so "life" may be taken as a category which includes the forms of all living things. (3:566, 3: 214; emphasis added)

Second, if the distinction between living and non-living beings is obliterated, then this puts a study of organisms as organisms beyond the reach of science. If there were no such things as living bodies, then there can be no life science. Moreover, even if we were to ignore this problem and presume that there is something unique about living bodies for Descartes, we intuitively believe that a scientific study of them would want to account, for example, for their self-preservative behavior, but not for their ability to entertain us in a fight to the death with another dog. But Descartes' Sixth Meditation account, 'especially when seen in light of Aristotle's thoughts on teleology, cannot provide a way of grounding this intuitive belief in a theoretical scientific framework that would give rise to a science of life. Of course, we could give scientific accounts for the lawful behavior of particles of matter that make up a dog's body, just as we can give such an account for the particles of matter which make up a clock's body. But there seems to be no way for Descartes to ground a science of life per se. Once again, this runs afoul of Aristotle's understanding of theoretical sciences and their scope, and once again, this runs afoul of Descartes' approach to natural science. His life as a scientist is premised on there being a distinction between living and non-living beings, and on the assumption that the range of phenomena to be explained within a science of life do not include, for example, the ability of dogs to entertain us in a fight to the death with another dog. So, for example, on 18 December 1629, he writes to Mersenne that he was beginning a study of anatomy ( $\mathrm{r}:$ IO2), and by this, he means the study of the structure of plant, animal, and human bodies, not a study of the structure of clocks and fountains. From this date forward, his working life as a scientist would include a distinct study of living beings, the fruits of which appear in many of his written works. And the range of phenomena which occupied him in his study of living bodies were roughly those we would intuitively believe appropriate for a working 
life scientist: nutrition, growth, reproduction, embryology, and so forth (obvious examples of this are found in Treatise on Man, Description of the Human Body, and Excerpta anatomica). If we take seriously, as we should, the belief that "Descartes was a scientist before he was a metaphysician" (Hatfield 1993, p. 259), and that his metaphysics (such as appears in the Meditations, including the Sixth Meditation passage upon which I have been focusing) is designed at least in part to provide supporting foundations for his science (e.g. 3: 298, 3: 173), then Descartes' apparent inability to secure a science of life because of the demands of the metaphysics of the Sixth Meditation poses a serious problem for him.

One way of trying to mitigate this problem is to use what Aristotle calls incidental ends - ends found in a mind extraneous to living beings to explain both how the things of the world are categorized and how the things of the world are then studied in the specialsciences. So, for example, we may say that a Cartesian science of life depends first upon a life scientist dividing the things of the world into living and non-living by saying that the first sorts of things are those which strive for self-preservation and do so through specific kinds of functions (nutrition and so forth), while also recognizing that these characteristics are extraneous labels, dependent upon purposes found in her own mind and not in the nature of things in the world. And then she could go about studying these teleological behaviors, once again recognizing that she is studying purposes in the living being as she conceives of them, and not as they are actually found in the (so-called) living being itself. However, there is a problem with this approach, namely, that it is a violation of the general spirit of Descartes' approach to science, which is not meant to be an undertaking based in human convention (purposes within a human's mind vis-à-vis the things of the world) but which is meant to be an undertaking which uncovers the true nature of the world.

One way of muting this problem is to agree that only the human composite has an intrinsic, end-referred nature to preserve itself and thus stay alive; no non-ensouled living bodies have such a nature. But, we can extend our legitimate teleological conclusions about ourselves to other bodies we call living, such as those of animals, because of the structural similarities between the human body and such bodies. Thus, all bodies we call living could be treated as if they tiad self-preservative natures, and

Is Plants, too, may be seen to have șimilar structures to those of animals. On early modern and other historical attempts to find analogues of various essential animal organs in plants, see Delaporte [1979] 1982. 
these natures could help to identify the class of bodies to be treated in a science of life. So while it is true that the life sciences would have as their subject a collection of beings identified by. human convention, it would not be an arbitrary convention but rather one grounded in the structural similarity that living bodies have with the human body, which does have a genuine, intrinsic end-referred nature to preserve itself. ${ }^{16}$

I suggest a second solution to the difficulty - a solution I can only outline in the broadest of strokes, and which demands more careful treatment elsewhere. According to this solution, Descartes can allow (even if he does not do so explicitly) that purely material things have intrinsic end-referred natures, albeit not at the level of ground-floor metaphysics of matter; the metaphysics of matter is his focus in the Sixth Meditation passage. At the physical level, one might argue, living beings behave in certain ways that non-living things do not because of their physical natures as found in the specific disposition of essential organs and parts. Living beings function in specific ways (they grow, repair themselves, and so on), for the overall goal of self-preservation. This account is teleological in some way at least - the disposition of parts that bodies have allow them to function so as to preserve themselves. ${ }^{17} \mathrm{On}$ an especially bold account of this teleological nature of living bodies, the design and function can even come about by chance and environmental pressures, which is both suggested by Lucretius in his On the Nature of Things, which Descartes read, and in concert with Descartes' own chaos 'fable' of the origins of all things (II: $34-35$, I: 9I; cf. 6: $42 ; 8 \mathrm{~A}$, IO2-3) ${ }^{18}$ That is, there can be a functioning design without a designer. ${ }^{19}$

This intrinsic end-referred physical nature may rely on a weaker form of teleology than does the metaphysical nature that human composites have, but it could be robust enough to categorize the things of the world according to features of the world itself (and not merely epistemological features of the categorizer), and to be scientifically useful. Descartes could then distinguish (physically) between, on the one hand, the intrinsic ends of self-preservation and the bodily functions which contribute to self-preservation which are grounded in the living being's nature, and, on

${ }^{16}$ I am indebted to Tad Schmaltz for drawing my attention to this solution. Carriero (2009), pp. 4 I7f. suggests something similar as a way of explaining disorder in bodies.

$17 \mathrm{I}$ take it Des Chene would dissent from my characterization of this kind of physical nature as teleological. See Des Chenes (200I), pp. I2sff.

${ }^{18}$ For a discussion of Lucretius' text and reception in the early modern period, including on this point, see Johnson and Wilson (2007).

19 On this in contemporary philosophy of biology, see Kitcher (1998). 
the other hand, mere incidental ends, such as entertaining us in a fight to the death, which are not grounded in a living being's nature but rather in a user's purpose vis-à-vis the living being. The former, but not the latter, would be the phenomena studied in the life sciences. This account would have the added appeal of showing that Descartes presages a crucial conceptual point in later biology, namely, that we can be reductionist in our explanatory accounts of living bodies without thereby eliminating the category of living beings. ${ }^{20}$

This approach would favor the third interpretation of the composite's nature explored in the previous section. The soul recognizes value in the body, ${ }^{25}$.but the value is at the level of physical dispositions of parts, not the metaphysics of matter. It is a value shared by: other physical things, such as dogs and other living beings. Thus, there are two forms of teleology at work in this account of the composite. First, the human body (as with other living bodies) has a teleological nature of the kind just described. It is teleology that could be non-Platonic (were it to arise without a designing mind having made it) and non-Aristotelian (there is no intrinsic, end-referred efficient cause or principle of change that accounts for the being's functions, all of which can be explained in wholly mechanical terms). Second, the human being (uniquely) has a Platonic teleological nature in that the human mind recognizes the value of the well-functioning physical machine that is its living body. But this is Platonic teleology of an innocuous kind for Descartes, because the mind recognizing the value of the machine is not God's mind, and so we are not making claims about God's purposes.

If I can establish that Descartes can leave room for intrinsic, endreferred natures at the level of the physical - I do not pretend that this is going to be an easy thing to show ${ }^{22}$ - then all tensions would be solved. What Descartes says about non-ensouled living bodies in the Sixth Meditation (Feature 2) would be a comment about their metaphysical natures, and as such, they indeed do not have intrinsic end-referred natures. What he says about non-ensouled living bodies in his biological works (Feature 3) would be a comment about their physical natures, which do have intrinsic end-referred natures. Descartes' prohibition of

${ }^{20}$ Gaukroger (2000 and 2010) argues that Descartes is a reductionist but not an eliminativist about life.

${ }^{21}$ As Lisa Shapiro has pointed out to me, one element of this broad sketch that especially deserves attention is the nature of the "value" that the soul recognizes in a healthy body. On this, see Shapiro (2003). Hoffman's (2009b) account of conceptions of final causes of varying strengths is also helpful on this front.

${ }^{22}$ Helpful precedents for showing this, include Hatfield (1992 and 2008). 
teleological explanations in natural philosophy (Feature I) is a prohibition against Platonic teleology where the mind of God (as maker) is the external agent. ( $\mathrm{He}$ is also opposed to Aristotelian teleology.) Thus, there is no tension between this feature and his account of the intrinsic end-referred nature of the human composite (Feature 2), which relies on other forms of teleology. Similarly, there is no tension between his prohibition of very specific forms of teleology (Feature I) and the different form of teleology he uses in his biological works (Feature 3). Admittedly, one significant problem would remain, and that is the problem of how to account for the unique unity of the human mind with its body. It is a problem that followed Descartes well into his later years, and turning to his work in those years may well be necessary to fully make sense of the Sixth Meditation on this point. 